\title{
TRANEXAMIC ACID IN THE MANAGEMENT OF BLOOD LOSS IN TKA
}

\author{
Kalin Mihov, Svetoslav Dobrilov, Maksim Zagorov, Todor Gerov, Aleksandar Gospodinov, \\ Gergana Nenova
}

\author{
Department of Ortopedics and Traumatology, Universiy Hospital "St. Marina", \\ Faculty of Medicine
}

\begin{abstract}
Total knee replacement is one of most common orthopedic procedures, which is associated with significant blood loss. Administration of tranexamic acid is one of the methods to decrease the perioperative bleeding and haemotransfusion necessity. In the Dept. of Orthopedics and Traumatology, 383 TKA have been performed since 2013. In 250 patients $500 \mathrm{mg}$ IV were administered $10 \mathrm{~min}$ prior to first incision and $500 \mathrm{mg}$ IV - at tourniquet release. Topical use of tranexamic acid (TXA) was applied in 58 cases. $1.5 \mathrm{~g}$ TXA in $100 \mathrm{cc}$ $\mathrm{NaCl}$ for $3 \mathrm{~min}$ before deflation was administered to the patients. Peri- and postoperative blood loss, hemoglobin level decrease and transfusion requirements were observed. Results showed about $\mathbf{4 5} \%$ lower bleeding than the control group compared to IV use and about $15 \%$ less bleeding compared to the topical application group. All the patients from the control group required blood transfusion after surgery due to blood loss - about $890 \mathrm{ml}$ on average. The topical application group showed average blood loss of $560 \mathrm{ml}$ and the IV group - about $460 \mathrm{ml}$. None of the patients with IV application of TXA required blood transfusion. Blood loss in the groups with administer TXA, IV or topical, was significantly lower with better results in IV application. Administration of TXA is a safe and reliable method for reducing bleeding associated with TKA which decreases the necessity of haemotransfusion.
\end{abstract}

Keywords: TKA, tranexamic acid, blood loss, tourniquet

\section{INTRODUCTION}

Total knee replacement arthroplasty (TKA) is one of the most commonly executed orthopedic surgeries. TKA gives the patients significant pain relief and better quality of life but it is also associated with noticeable blood loss due to surgical technique and bone resection. Blood loss in total knee replacement depends on different factors such as patient characteristics (general health, comorbidi-

Address for correspondence:

Kalin Mihov

"Hr. Smirnenski "Blvd 1

University Hospital "St. Marina"

Department of Ortopedics and Traumatology

e-mail: kalinmihov@mail.bg

Received: September 10, 2016

Accepted: December 12, 2016 ties, anticoagulation drugs, etc.) and surgical techniques (bone resections, soft tissue cuts, tourniquet time, operative time). Bleeding in every surgical procedure generally can be separated to visible (measured) - aspiration, gases, drainage and hidden (unmeasured) which could be $40 \%$ of all blood loss. Increased blood loss during TKA is a prerequisite for postoperative anemia, wound infection, pain, hemarthrosis, delayed rehabilitation, arthrofibrosis, prolonged hospitalization, increased expenses and most importantly - need for blood transfusion. Controlling blood loss during and after surgery is an important element to accomplishing good results in TKA. Intraoperatively it is done by controlled hypotension, decreased surgical dissection, preserving intramedullary canal, use of individual/cemented implants, bone wax, hypothermia, local infiltration anesthesia (LIA), tourniquet and inhibitors of fibrinolysis - 
Kalin Mihov, Svetoslav Dobrilov, Maksim Zagorov et al.

tranexamic acid (TXA). Postoperative blood loss increases up to 3 times in the first 8 hours. The most common procedures for controlling it are: drainage, elevation, knee flexion for 4-6 h, analgesia, hypotonia, autohemotransfusion systems (low debit, expensive). Haemotransfusion is not a safe procedure and it is frequently associated with a lot of possible risks like transmissive infections, acute systemic reactions and higher thromboembolic risks. Blood loss was determined by measuring the level of suction fluid, a decrease of $\mathrm{Hb}$ and Erytrocytes and postoperative suction drainage. One of the methods for reducing the bleeding is to use tranexamic acid during TKA surgery. There is sufficient literature evidence concerning the efficacy of natural (aprotinin) or synthetic (tranexamic acid) antifibrinolytic agents in reducing blood loss and transfusion requirements in orthopedic surgery. Nowadays, the tourniquet is routinely used in TKA. It not only reduces blood loss during operation but also makes a clear operation area. However, it should be emphasized that the use of tourniquet activates the local fibrinolytic system and greatly increases blood loss after the operation. Tranexamic acid (TXA) is an analog of lysine, which has powerful antifibrinolytic potency through blocking the lysine-bonding sites of the plasminogen molecule and is mainly used in bleeding caused by acute or chronic, localized or systemic accentuation of fibrinolysis.

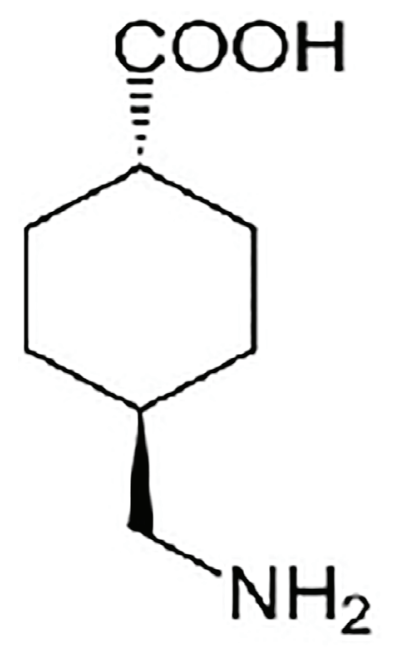

Fig. 1. Tranexamic acid molecule

\section{PATHOPHYSIOLOGY AND PHARMACOKINETICS}

Surgery damage occurs in the endothelium of blood vessels which results in the exposure of collagen and release of tissue factors. These factors and exposed collagen activate the extrinsic and intrinsic coagulation cascade and form thrombin and allow the creation of clots with the assistance of platelets. Blood clots prevent excessive blood loss.

Surgery and venous stasis stimulate the release of tissue plasminogen activator (t-PA), activating the fibrinolytic system. This t-PA is the main factor responsible for the conversion of plasminogen into active plasmin. Fibrinolytic activation is a cascade-like process, which is easily inhibited in its early phase. TXA prevents clot lysis more effectively when administered before clot formation, than after the fibrin clot is formed. Once plasminogen is bound to the fibrin surface, TXA is no longer effective. This may explain why TXA has limited effect when administered at the end of surgery.

The fibrinolytic process after surgery is biphasic. In the first stage the fibrinolytic activity is increased during the first hours, followed by a fibrinolytic decrease that peaks at about $24 \mathrm{hrs}$. Decreased activity is related to a high level of plasminogen activator-inhibitor (t-PAI) that inactivates t-PA. So there is a natural inhibition of the fibrinolytic process and while early administration of the first dose of TXA seems to be important, a second bolus dose after 3 hrs or starting a continuous infusion seems not to augment the effect.

Tranexamic acid has a half-life of about 2-3 hours. It has renal excretion. In adults, tranexamic acid is typically administered with a loading dose of $10 \mathrm{mg} / \mathrm{kg}$, followed by infusion of $1 \mathrm{mg} / \mathrm{kg} / \mathrm{h}$. There is a lot of data about usage doses between 10 and 20 $\mathrm{mg} / \mathrm{mg}$. In those studies, tranexamic acid has been shown to be effective in reducing blood loss, decreasing the necessity of blood products.

TXA can generally be administered intravenously: 1) $1 \mathrm{~g}$ TXA IV prior to incision and $1 \mathrm{~g}$ TXA IV after tourniquet deflation; 2) $2 \mathrm{~g}$ IV prior to incision - usually when TKA is done without tourniquet; $10 \mathrm{mg} / \mathrm{kg}$ before surgery and $3 \mathrm{~h}$ postoperatively. In a patient with renal dysfunction or other comorbidities TXA is administered locally orin a decreased 


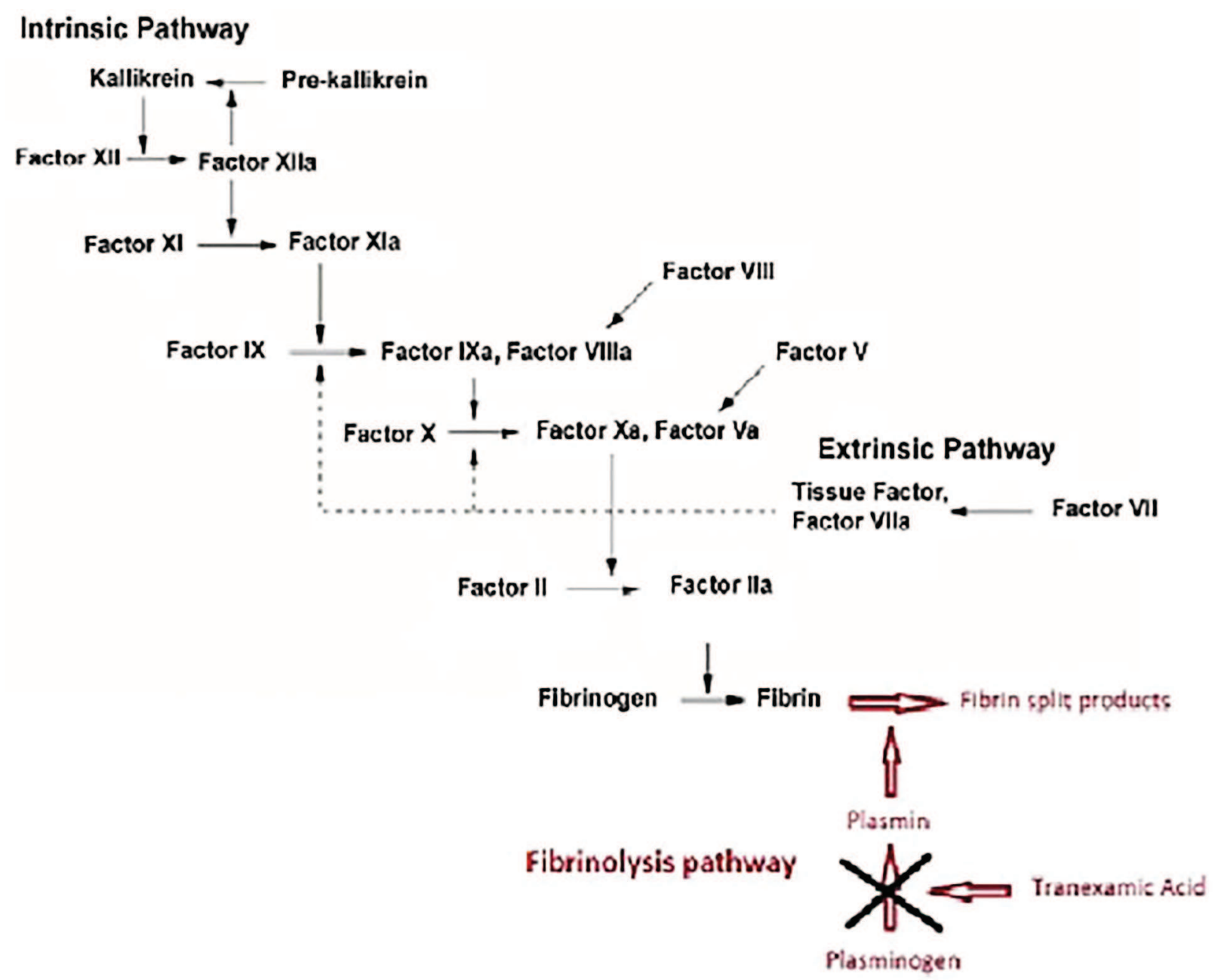

Fig. 2. Pathophysiology of clot formation

dosage. Local application: 1) $1.5 \mathrm{~g} / 100 \mathrm{ml} \mathrm{NaCl} 5 \mathrm{~min}$ before closure; 2) $1 \mathrm{~g} / 100 \mathrm{ml} \mathrm{NaCl}$ via drainage and clamping for $1 \mathrm{~h}$; 3) $1.5 \mathrm{~g} / 100 \mathrm{cc} \mathrm{NaCl}$ for 3 min after tourniquet deflation. The reason for local administration of TXA vs. intravenous is reducing systemic reactions.

Many studies and review articles have shown that tranexamic acid is efficient and does not increase greatly the possibility of a stroke, myocardial infarction, deep venous thrombosis, pulmonary embolism, and acute kidney failure (1).

\section{MATERIALS AND METHODS}

In the period 2013-06.2014 in the Dept. of Orthopedics and Traumatology 58 TKA were performed with local application of tranexamic acid for reducing postoperative blood loss. Patients were given $1,5 \mathrm{~g}$ TXA in $100 \mathrm{cc} \mathrm{NaCl}$ for 3 min before defla- tion. The local application is considered to be a safer method of delivery while decreasing system effects. Multiple studies and meta-analyses support the safety and efficiency of topical intraarticular administration of tranexamic acid (2-8). For a period of 3 years since 06.2014 over 250 TKA have been performed in the clinic. All patients have met the inclusion criteria which are: written consent and approval, diagnosis of osteoarthritis, no history of bleeding disorder or history of a venous thromboembolic disease. Exclusion criteria: allergy to tranexamic acid, preoperative renal or hepatic dysfunction, bleeding disorders and preoperative coagulation anomalies. All patients were treated with LMWH (Fraxiparine, Zibor) in the evening before surgery and it was continued postoperatively for six days.

The doses used during the surgery were: $500 \mathrm{mg}$ IV $10 \mathrm{~min}$ prior to first incision and $500 \mathrm{mg}$ IV at 


\section{Activation of fibrinolysis}

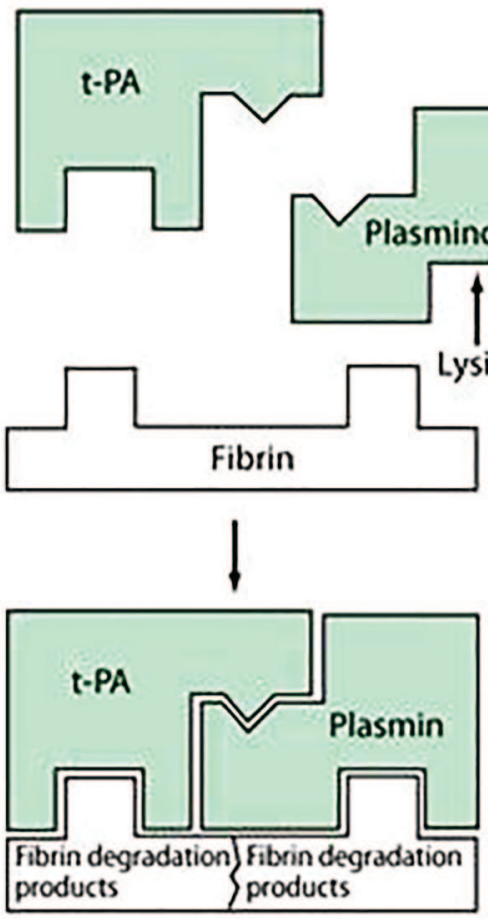

\section{Inhibition of fibrinolysis}

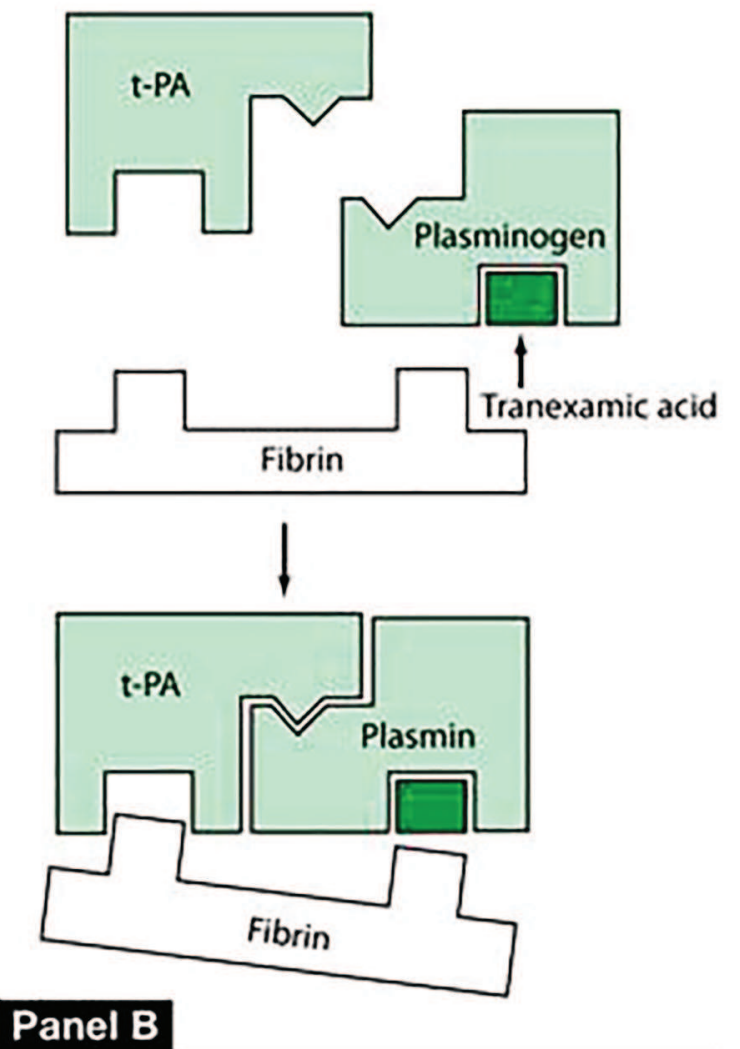

Fig. 3. Mechanism of TXA bonding

tourniquet release. The tourniquet is inflated to a pressure of $350 \mathrm{mmHg}$ to $400 \mathrm{mmHg}$ and we use a cemented type of prosthesis. We place one intraarticular drainage, which is removed two days after the operation. Rehabilitation is started on the first postoperative day.

\section{RESULTS}

The three groups were comparable for age, gender, weight, tourniquet time and duration of sur- gery. Obviously, the blood loss in the groups given tranexamic acid is significantly lower. We have about $45 \%$ less bleeding than the control group compared to IV use and about $15 \%$ less bleeding compared to the topical application group. All the patients who didn't use tranexamic acid needed a blood transfusion after surgery due to severe blood loss - about 890 $\mathrm{ml}$ on average. The IV use of tranexamic acid showed best results in terms of blood loss averaging at about

Tabl. 1. Details of the patients from all three groups

\begin{tabular}{l|ccc|} 
& Control Group & Topical Application & IV Application \\
Number of Patients & 75 & 58 & 250 \\
Age & $69 \pm 6$ & $68 \pm 12$ & $71 \pm 9$ \\
Weight & $75 \pm 5$ & $72 \pm 8$ & $78 \pm 15$ \\
Duration of Surgery & $85 \pm 10$ & $85 \pm 10$ & $85 \pm 10$ \\
Tourniquet Time & $65 \pm 10$ & $65 \pm 10$ & $65 \pm 10$ \\
\hline
\end{tabular}


Tabl. 2. Mean (range) blood loss

\begin{tabular}{l|ccc} 
& Control Group without TXA & Topical Application & IV Application \\
\hline Number of Patients & 75 & 58 & 205 \\
Blood Loss $(\mathrm{ml})$ & $890 \pm 230$ & $520 \pm 90$ & $460 \pm 70$ \\
Average Hb Level $\downarrow$ & $35 \mathrm{~g} / \mathrm{l}$ & $20 \mathrm{~g} / \mathrm{l}$ & $18 \mathrm{~g} / \mathrm{l}$ \\
\hline
\end{tabular}

$460 \mathrm{ml}$ per patient. None of the patients with IV application of TXA required a blood transfusion.

\section{DISCUSSION}

There are different methods of administering tranexamic acid with the purpose to lower blood loss in TKA: oral, intramuscular, intravenous and intraarticular. In order to achieve maximum plasma levels of TXA, application prior to surgery should be 5 to 15 minutes for intravenous administration, 30 minutes for intramuscular and two hours for oral administration $(9,10)$. Ahlberg, Eriksson and Kjellman (11) described that tranexamic acid which is given intravenously diffused fast into the synovia and thus there was an reason to inject it intra-articularly. An intravenous injection for patients undergoing TKA is the best method for postoperative rehabilitation and maintaining the therapeutic concentration of tranexamic acid in the knee during and after surgery. Pharmacokinetic studies $(12,13)$ demonstrated that a dose of $20 \mathrm{mg} / \mathrm{kg}$ of TXA is suitable for TKA considering therapeutic levels can be maintained for around eight hours after surgery, which in general is the period of hyperfibrinolysis in cases of increased blood loss. Several clinical studies have exposed the efficacy of TXA when given before surgery $(14,15)$ or on release of the tourniquet $(16,17)$. Two aspects were clarified in our study - the blood loss in TKA was lowered by more than $40 \%$ after the administration of tranexamic acid compared to the control group and the hemostatic effect was best when TXA was administered preoperatively and once more on deflation of the tourniquet. There are two applications of tranexamic acid, one given preoperatively and one on deflation of the tourniquet, significantly lowering blood loss, associated with TKA performed with a tourniquet, without increasing the risk of thromboembolic complications.

There are a few case reports which show that tranexamic acid is associated with a higher rate of pulmonary embolism (PE) and deep vein thrombosis (DVT) $(18,19,20,21)$. There are some researches dedicated to this. Cochrane's review showed that tranexamic acid does not significantly increase the risk of deep vein thrombosis, pulmonary embolism, stroke and control group (25). CRASH-2 study with more than 20000 trauma patients with hemorrhage does not show a statistical increase in vascular occlusive events (26). There is a meta-analysis (24) of randomized controlled trials investigated the efficacy and safety of the intravenous use of TXA in TKA. And the conclusion is that TXA is cheap and very effective in reducing blood loss. TXA reduced the number of patients who needed transfusion by $30 \%$ and the decreased average volume of blood transfusion reached 0.95 unit. TXA also did not raise the risks of DVT or PE.

Because of decreasing blood transfusion necessity, TXA decreases many possible risks associated with it such as infection, acute systemic reactions, etc. Administration of TXA is very cost-effective by reducing by more than $80 \%$ need of a transfusion. 3 Amp TXA are more than 10 times cheaper than 1 unit of packed cells.

\section{CONCLUSIONS}

TXA is a safe and reliable method for reducing bleeding associated with TKA. A single dose of 500 $\mathrm{mg}$ tranexamic acid given 5 minutes before surgery and $500 \mathrm{mg}$ at tourniquet release reduces the postoperative and total blood loss and the need for transfusions in knee arthroplasty surgery. This dose seems to be an adequate compromise between fibrinolytic inhibition by tranexamic acid in the early hyperfibrinolytic stage and the postoperative period of fibrinolytic shutdown. We use TXA in our standard blood management protocol in TKA. 
Kalin Mihov, Svetoslav Dobrilov, Maksim Zagorov et al.

\section{REFERENCES}

1. Selvaratnam V., Fountain J., Donnachie N., Thomas Th., Carroll F, Does Pre-Operative Tranexamic Acid Increase the Incidence of Thromboembolism in Primary Lower Limb Arthroplasty?, Open Journal of Orthopedics, 2013, 3, 249-252

2. Wong J, Abrishami A, El Beheiry H, Mahomed NN, Roderick Davey J, Gandhi R, et al. Topical application of tranexamic acid reduces postoperative blood loss in total knee arthroplasty: a randomized, controlled trial. J Bone Joint Surg Am. 2010; 92: 2503-2513.

3. Onodera T, Majima T, Sawaguchi N, Kasahara Y, Ishigaki T, Minami A. Risk of deep venous thrombosis in drain clamping with tranexamic acid and carbazochrome sodium sulfonate hydrate in total knee arthroplasty. J Arthroplasty. 2012; 27: 105-108.

4. Wind TC, Barfield WR, Moskal JT. The effect of tranexamic acid on blood loss and transfusion rate in primary total knee arthroplasty. J Arthroplasty. 2013; 28: 1080-1083.

5. Mutsuzaki H, Ikeda K. Intra-articular injection of tranexamic acid via a drain plus drain-clamping to reduce blood loss in cementless total knee arthroplasty. J Orthop Surg Res. 2012; 7: 32.

6. Georgiadis AG, Muh SJ, Silverton CD, Weir RM, Laker MW. A prospective double-blind placebo controlled trial of topical tranexamic Acid in total knee arthroplasty. J Arthroplasty. 2013; 28: 78-82.

7. Panteli M, Papakostidis C, Dahabreh Z, Giannoudis PV. Topical tranexamic acid in total knee replacement: A systematic review and meta-analysis. Knee. 2013; 20: 300-309.

8. Seo JG, Moon YW, Park SH, Kim SM, Ko KR. The comparative efficacies of intra-articular and IV tranexamic acid for reducing blood loss during total knee arthroplasty. Knee Surg Sports Traumatol Arthrosc. 2013; 21: 1869-1874.

9. Benoni G, Bjorkman S, Fredin H. Application of pharmacokinetics data from healthy volunteers for the prediction of plasma concentrations of tranexamic acid in surgical patients. Clin Drug Invest 1995;10:280-7.

10. Sano M, Hakusui H, Kojima C, Akimoto T. Absorption and excretion of tranexamic acid following intravenous, intramuscular and oral administrations in healthy volunteers. Jpn J Clin Pharmacol Therapeutics 1976;7:375-82.
11. Ahlberg A, Eriksson O, Kjellman H. Diffusion of tranexamic acid to the joint. Acta Orthop Scand 1976;47:486-8. Veenesh Selvaratnam*, James R. Fountain, Nigel J. Donnachie, Thomas G. Thomas, Fintan A. Carroll

12. Walzman M, Bonnar J. Effects of tranexamic acid on the coagulation and fibrinolytic systems in pregnancy complicated by placental bleeding. Arch Toxicol Suppl 1982;5:214-20.

13. Eriksson O, Kjellman H, Pilbrant A, Schannong M. Pharmacokinetics of tranexamic acid after intravenous administration to normal volunteers. Eur J Clin Phamacol 1974;7:375-80.

14. Jansen AJ, Andreica S, Claeys M, et al. Use of tranexamic acid for an effective blood conservation strategy after total knee arthroplasty. Br J Anaesth 1999;83:596-601.

15. Sakahashi H, Sato E, Ishima T. A means for control of bleeding during and after the artificial knee joint replacement operation (combined use of antiplasmin and the drain clamp method). Jpn Soc Replacement Arthroplasty 1998;28:67-8.

16. Benoni G, Fredin H. Fibrinolytic inhibition with tranexamic acid reduces blood loss and blood transfusion after knee arthroplasty: a prospective, randomised, double-blind study of 86 patients. J Bone Joint Surg [Br] 1996;78-B:434-40.

17. Hiippala ST, Strid LJ, Wennerstrand MI, et al. Tranexamic acid radically decreases blood loss and transfusions associated with total knee arthroplasty. Anesth Analg 1997;84:839-44.

18. Gybel M, Kristensen K, Roseva-Nielsen N. [Cardiac arrest caused by massive pulmonary embolism during treatment with tranexamic acid]. Ugeskr Laeger. 2013; 175: 1426-1427.

19. Taparia M, Cordingley FT, Leahy MF. Pulmonary embolism associated with tranexamic acid in severe acquired haemophilia. Eur J Haematol. 2002; 68: 307-309.

20. Krivokuca I, Lammers JW. Recurrent pulmonary embolism associated with a hemostatic drug: tranexamic acid. Clin Appl Thromb Hemost. 2011; 17: 106-107.

21. Bruce-Brand R, Dragomir R, Baker J, Harty J. Cerebrovascular infarction following bilateral total knee arthroplasty and tranexamic acid administration. Acta Orthop Belg. 2013; 79: 351-354.

22. Henry DA, Carless PA, Moxey AJ, O'Connell D, Stokes BJ, McClelland, B, et al. Anti-fibrinolytic 
Tranexamic Acid in the Management of Blood Loss in TKA

use for minimising perioperative allogeneic blood transfusion. Cochrane Database Syst Rev. 2011; CD001886.

23. CRASH-2 trial collaborators, Shakur H, Roberts I, Bautista R, Caballero

24. J, Coats T, et al. Effects of tranexamic acid on death, vascular occlusive events, and blood transfusion in trauma patients with significant haemorrhage (CRASH-2): a randomised, placebo-controlled trial. Lancet. 2010; 376: 23-32.

25. FU De-jie, CHEN Cheng, GUO Lin, YANG Liu* Use of intravenous tranexamic acid in total knee arthroplasty: a meta-analysis of randomized controlled trials

26. HO K. M., ISMAEL H. Use of intravenous Tranexamic Acid to reduce allogeneic blood transfusion in total hip and knee arthroplasty : a metaanalysis. Anaesth Intensive Care, 2003, 31 : 529-37.

27. Claeys M., Vermeersch N., Haentjens P, Reduction of Blood Loss with Tranexamic Acid in Primary Total Hip Replacement Surgery, Acta chir belg, 2007, 107, 397-401 